\title{
PERANCANGAN PURWARUPA BIRD REPELLENT DEVICE SEBAGAI OPTIMASI PANEN PADI DI BIDANG PERTANIAN BERBASIS INTERNET OF THINGS
}

\author{
Ahmad Roihan \\ Program Studi Sistem Komputer \\ STMIK Raharja \\ Email: ahmad.roihan@raharja.info \\ Muhaimin Hasanudin \\ Program Studi Sistem Informasi \\ STMIK Raharja \\ Email: muhaimin@raharja.info \\ Endang Sunandar \\ Program Studi Sistem Komputer \\ STMIK Raharja \\ Email: endang@raharja.info \\ Saria Rizki Pratama \\ Fakultas Sains dan Teknologi, Program Studi Sistem Komputer \\ Universitas Raharja \\ Email: saria@raharja.info
}

\begin{abstract}
ABSTRAK
Burung adalah salah satu binatang dari beberapa hama atau hewan perusak yang terdapat pada area persawahan. Luasnya area menjadi perhatian khusus bagi petani. Oleh karena itu petani menggunakan peralatanperalatan tradisional seperti tali plastik dan orang-orangan sawah untuk mengusir hama tersebut. Metode perancangan dan pengujian disertai automasi yang cerdas dibutuhkan sebagai jawaban dari masalah yang dialami oleh para petani. Perancangan purwarupa Bird repellent device bekerja dengan cara memanfaatkan teknik computer vision melalui sensor kamera untuk menangkap objek burung dalam setiap frame, kemudian diproses oleh Raspberry Pi. Setelah objek tertangkap pada kamera maka Raspberry Pi mengaktifkan aktuator berupa frekuensi suara. Penerapan sistem pengusir burung dilakukan secara otomatis dengan cara mendeteksi keberadaan burung, disertai teknik pengusiran dengan memanfaatkan frekuensi suara yang tidak disukai oleh burung, dan diharapkan dapat mengusir hama serangan burung. Pengujian dini dilakukan untuk mengetahui proses notifikasi melalui telegram berjalan dengan baik. Pengujian ini menunjukkan bahwa proses deteksi dengan menggunakan kamera dan konfigurasi komunikasi melalui internet sudah berhasil dan mendeteksi adanya burung. Sejalan dengan notifikasi, aktuator pun berjalan sebagaimana mestinya.
\end{abstract}

Kata kunci: Serangan burung; bird repellent device; persawahan.

\section{ABSTRACT}

Bird is one of the animals from several pests or destructive animals found in rice fields. The vast area of rice fields is of particular concern for farmers. Therefore farmers use traditional tools such as plastic ropes and scarecrow to keep the pests away. Design and testing methods with intelligent automation will answer farmers' problems. The design of the Bird repellent device works by utilizing computer vision techniques through camera sensors, it will capture birds in each frame, it is processed and controlled by the Raspberry Pi. The implementation of the bird repellent system will automatically detect the presence of the bird, then the tool runs an eviction technique utilizing the sound frequencies that are disliked by birds, so that it can repel bird strikes. The results of the early testing obtained notification via telegram went well. This test shows that the detection process using a camera and configuration of communication via the internet has been successful and has detected birds. In line with the notification, the actuator is running as it should.

Keywords: bird strikes; bird repellent device; rice field. 


\section{PENDAHULUAN}

Pada saat ini, teknologi semakin berkembang dengan sangat cepat dan semakin canggih. Cepatnya perkembangan teknologi ini pastinya sangat berkaitan dengan perkembangan teknologi pendukungnya seperti komponen elektronika. Komponen elektronika saling berintegrasi menjadi satu kesatuan dalam satu chip dan memiliki peran sebagai register, arithmetic logic unit, serta control unit yang mampu mengendalikan beberapa perangkat elektronika lain yang sering dikenal dengan mikroprosesor.

Penggunaan teknologi dalam bidang pertanian merupakan faktor penting dalam pengembangan sektor pangan saat ini. Selain mengurangi waktu panen, teknologi juga menawarkan kemudahan yang disediakan oleh beberapa badan penelitian. Meskipun memiliki beberapa keuntungan dari teknologi, terkadang ada juga masalah yang sering ditemukan pada waktu tertentu misalnya saat menjelang masa panen. Adapun masalah yang sangat sering terjadi pada masa panen ini adalah serangan burung [1].

Secara tradisional, teknik mengusir burung sebenarnya telah diterapkan di beberapa persawahan. Bentuk upaya yang telah dilakukan oleh petani yaitu menggunakan alat tradisional seperti kentungan dengan berkeliling sawah yang cukup luas, pembuatan orang-orangan sawah, penggunaan jaring hingga teknologi pemasangan alat pendeteksi kehadiran burung dan cara mengusirnya [2][3]. Jika dilihat dari rantai makanan, maka sawah merupakan tempat makanan yang berlimpah dan area yang cocok untuk berkembang biak bagi burung. Hal ini menjadi tantangan bagi beberapa pihak yang terlibat dalam konservasi alam dan ekosistem lingkungan sehingga habitat burung dapat dipertahankan di lingkungan aslinya tanpa harus menggangu petani pada masa panen.

Waktu yang kritis bagi tanaman padi diserang burung yaitu ketika pagi dan sore hari. Beberapa cara untuk mengantisipasi kelelahan pun dilakukan oleh petani, diantaranya petani juga mempekerjakan orang untuk menjaga sawah. Dilihat dari segi ekonomi, langkah ini jelas tidak efisien karena petani harus kembali mengeluarkan biaya guna pengusiran burung. Masalah lainnya yaitu banyaknya hama burung yang mengakibatkan kurang optimalnya hasil panen, kemudian petani tidak dapat menjaga secara real time serta biaya yang cukup besar untuk proses pengusiran burung.

Saat ini penelitian dalam observasi terhadap serangan burung baik di ladang angin [4] dan di sekitar persawahan [5] sudah dilakukan dan terus dikembangkan. Secara bertahap penelitian tentang penggunaan perangkat sensor, aktuator dengan mikrokontroler semakin berkembang. Beberapa diantaranya digunakan dalam proses monitoring [6], alat ukur [7], simulator [8], dan lain sebagainya.

Ruang lingkup penelitian terbatas pada perancangan dan pengujian alat purwarupa bernama bird repellent device yang berbasis Raspberry $\mathrm{Pi}$, dapat diakses secara jarak jauh dan proses pemantauan menggunakan Internet of Things pada persawahan kecamatan labuan. Rancangan alat dengan menggunakan Raspberry Pi, instalasi dan konfigurasi untuk menambahkan alat ini agar bisa diakses secara global melalui internet dan hasilnya dapat diuji untuk diimplementasikan di area persawahan. Dengan memanfaatkan kecerdasan buatan, diharapkan tidak menutup kemungkinan hanya dengan data pengetahuan yang terbatas, sebuah komputer dapat berpikir seperti manusia dalam menghadapi masalah [9] seperti serangan burung.

Tujuan yang ingin dicapai dalam penelitian ini yaitu dapat mensterilkan persawahan dari hama burung sehingga dapat mempermudah pekerjaan para petani dan berdampak positif terhadap optimasi hasil panen padi. Pekerjaan petani dalam proses mengusir burung selama ini dapat terbantu atau tergantikan oleh alat ini dan dapat memanfaatkan waktu lebih maksimal agar lebih produktif. Alat ini mengeluarkan frekuensi suara yang dapat mengganggu burung. Frekuensi berupa suara yang dikeluarkan akan dapat membantu petani untuk mengusir hama burung pada sawah sehingga dapat mengoptimalkan hasil panen padi. Tujuan lainnya yaitu menyediakan kumpulan data video untuk kepentingan penelitian computer vision dan pengolahan citra dalam area persawahan berbasis Internet of Things.

\section{METODOLOGI PENELITIAN}

Metode pengumpulan data yang dilakukan dalam peenelitian ini terdiri dari beberapa metode, antara lain pengamatan, wawancara dan studi pustaka. Metode observasi (pengamatan) merupakan cara pengumpulan data dimana penelitian terlibat langsung ke lokasi penelitian. Dalam hal ini penelitiannya perlu mengunjungi persawahan Kecamatan Labuan sebagai lokasi penelitian untuk mengamati berbagai hal atau kondisi yang ada di lapangan. Dengan cara ini penelitian diharapkan dapat mengetahui dan memahami yang akan peneliti analisa pada Persawahan Kecamatan Labuan. Tahapan lainya yaitu wawancara yang merupakan salah satu cara yang dilakukan untuk memproses data dengan cara melakukan tanya jawab secara langsung dari pihak pengumpulan data dalam hal ini penelitian kepada kelompok tani dan tim pelaksana tugasnya sebagai narasumber atau sumber data. Metode studi kepustakaan pun dilakukan untuk menunjang metode observasi dan wawancara. Dengan cara mengambil intisari dari sumber literatur berupa buku, artikel dan lain-lain yang berhubungan dengan penelitian ini, termasuk referensi dari internet mengenai serangan burung di area persawahan.

Metode perancangan dan pengembangan dilakukan peneliti untuk mengetahui bagaimana proses sistem ini dirancang dan komponen apa saja yang dibutuhkan. Jika masih terdapat kekurangan sesuai kebutuhan sistem, maka proses pengembangan akan terus berjalan hingga pengujian dapat dilakukan secara akurat dan tepat. Metode ini 
dimaksudkan untuk mendapatkan suatu rangkaian alat yang tepat sehingga diperoleh prototipe atau rancangan purwarupa yang sesuai dengan yang diharapkan [10].

Metode analisa digunakan untuk mengetahui akar penyebab suatu permasalahan sehingga tepat sasaran. Analisa yang digunakan dalam menyusun laporan ini adalah Siklus PDCA (Plan, Do, Check, Action). Dengan metode ini memungkinkan penulis memecahkan suatu masalah yang dimulai dari mengumpulkan semua permasalahan yang ada hingga pada menetapkan suatu solusi dan mengimplementasikan solusi tersebut.

Metode Prototipe adalah proses pembuatan model sederhana software yang mengizinkan pengguna memiliki gambaran dasar tentang program serta melakukan pengujian awal. Purwarupa memberikan fasilitas bagi pengembangan dan pemakaian untuk saling berinteraksi selama proses pembuatan, sehingga pengembang dapat dengan mudah memodelkan perangkat yang akan dibuat.

Peneliti menerapkan prototipe dengan menggunakan evolutionary (sebab evolusi itu terjadi), hal ini dikarenakan hasil dari purwarupa tidak langsung dibuang tetapi digunakan untuk iterasi desain berikutnya. Dalam hal ini, sistem atau produk yang sebenarnya dipandang sebagai evolusi dari versi awal yang sangat terbatas menuju produk final atau akhir.

Metode pengujian dilakukan suatu percobaan atau praktek merakit sebuah alat pengusir burung berbasis Raspberry Pi yang dapat dikonfigurasi secara mobile Phone/PC. Raspberry Pi atau yang juga dikenal sebagai RasPi adalah sebuah SBC (Single board computer) seukuran kartu kredit yang paling populer berbasis sistem operasi linux. Raspbian adalah sistem operasi open source yang bersumber dari sistem operasi debian [11].

\section{HASIL DAN PEMBAHASAN}

Pengawasan area pertanian masih menggunakan metode manual sampai saat ini, yaitu dengan cara membuat orang-orangan sawah, menggunakan benda-benda mengkilap seperti plastik, menggunakan jaring sebagai perangkap dan lain sebagainya. Oleh karena itu, butuh alat pendukung yang sistematis yang mendukung automasi dan memanfaatkan kecerdasan buatan yang dapat berfungsi sebagai sesuatu yang dapat berpikir layaknya manusia [12].

Dalam pembuatan sebuah sistem diperlukan sebuah gambar yang akan dapat menjelaskan alur atau langkahlangkah dari sebuah kerja sistem yang dibuat, sehingga dapat memberikan penjelasan dalam bentuk gambar. Penjelasan yang berupa gambar proses kerja sebuah sistem merupakan gambar dari sistem yang akan dibuat. Tujuan dari pembuatan flowchart adalah untuk mempermudah pembaca dan pembuat sistem itu sendiri untuk memahami langkah-langkah serta cara kerja sebuah sistem yang dibuat. Flowchart (Diagram alir) dapat didefinisikan sebagai gambaran kinerja suatu proses yang terurut dengan menggunakan simbol-simbol dan setiap urutannya mewakili fungsi dalam mempresentasikan sebuah alur yang disusun secara sistematis seperti yang tersusun dalam Gambar 1 berikut.

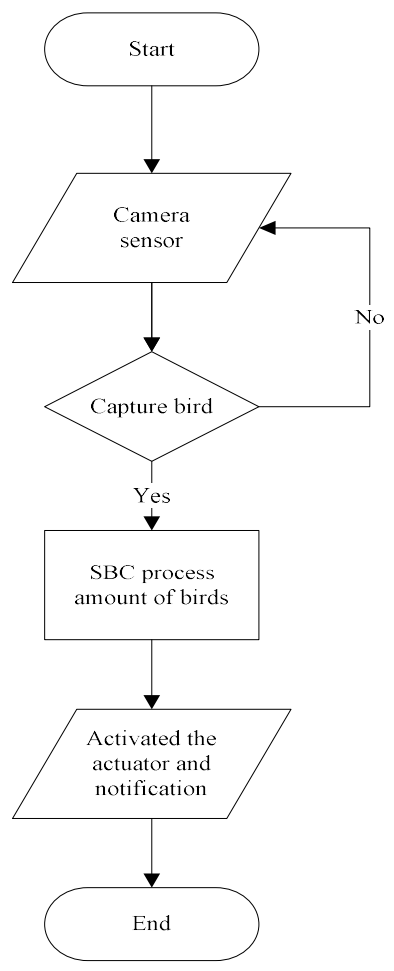

Gambar 1. Diagram Alir Sistem Bird Repellent Device 
Proses perancangan terdiri dari dua tahap yaitu perancangan perangkat keras (hardware) dan perangkat lunak (software). Dalam perancangan perangkat keras dibutuhkan beberapa alat dan bahan agar sistem dapat berjalan dengan baik sesuai dengan fungsinya. Dalam perancangan perangkat keras ini, alat dan bahan yang dibutuhkan seperti kamera sebagai sensor, SD card sebagai penyimpan sistem operasi dan perangkat lunak pendukung yang terintegrasi ke dalam Raspberry Pi, A6 serial modul GSM sebagai alat komunikasi, speaker sebagai aktuator, panel surya dan baterai

Pada rancangan sistem usulan ini peneliti membuat bird repellent device menggunakan Raspberry Pi untuk mengusir serangan burung yang ada pada persawahan secara langsung, alat pengusir burung ini ditempatkan di sekitar persawahan sebagai optimasi hasil panen padi di sawah. Bahan peralatan yang akan digunakan, peneliti susun dalam diagram blok (Gambar 2) sebagai bahan untuk melengkapi dan mendukung kinerja sistem diagram alir yang telah dibuat sebelumnya.

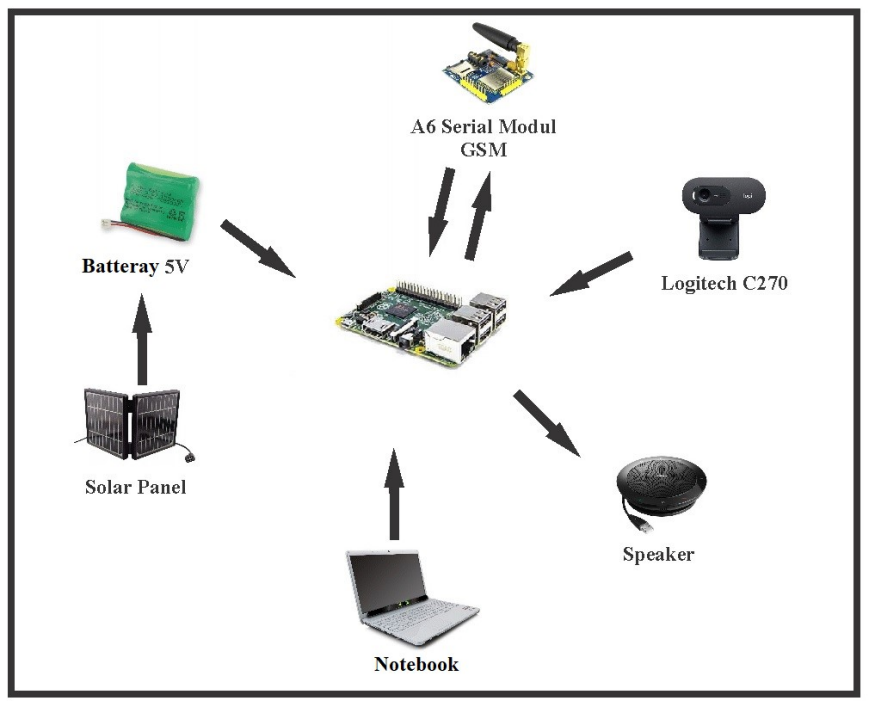

Gambar 2. Diagram Blok Bird Repellent Device

Pada Gambar 2 terlihat bahwa Raspberry Pi sebagai mikroprosesor yang mengintegrasikan beberapa perangkat seperti serial modul GSM, sensor kamera, aktuator berupa speaker. Kemudian laptop atau notebook merupakan perangkat yang berfungsi untuk input dan pengolahan data awal untuk Raspberry Pi. A6 Serial Modul GSM berfungsi untuk jaringan IoT pada Raspberry Pi. Sedangkan sensor yang digunakan dalam penelitian ini yaitu kamera Logitech C270 yang bertugas sebagai bahan masukan dan merupakan perangkat media mendeteksi objek. Baterai $5 \mathrm{~V}$ berfungsi untuk cadangan listrik yang terintegrasi dengan panel surya sebagai produk energy atau sumber tegangan dari sinar matahari yang nantinya akan menjadi listrik dan tersimpan ke dalam baterai. Selanjutnya speaker sebagai aktuator yang berfungsi untuk mengeluarkan frekuensi suara.

Cara kerja alat ini dari segi perangkat keras cukup kompleks dimana Raspberry Pi digunakan untuk menyatukan semua perangkat seperti serial modul GSM, kamera, speaker, dan ketika perangkat tersebut sudah berjalan. Sensor kamera berfungsi sebagai media penangkap citra dan sekaligus pemantau burung yang dijadikan sebagai deteksi objek untuk mengetahui keberadaan burung. Jika pada saat itu terdeteksi ada burung maka system akan langsung menginstruksikan speaker untuk mengeluarkan suara.

Dalam perancangan perangkat lunak terdapat beberapa software yang harus disiapkan untuk proses instalasi dan konfigurasi seperti sistem operasi Raspbian, SDformatter, Win32Disklmager, advanced IP Scanner dan PuTTY. Secara garis besar langkah-langkah instalasi Raspbian dapat dilakukan secara langsung dalam Rasberry Pi, namun proses instalasi sistem operasi dalam penelitian ini menggunakan media laptop dengan sistem operasi Windows.

Instalasi sistem operasi Raspbian pada micro SD dilakukan dengan memanfaatkan software SDformatter yang mana kartu microSD ini dimasukkan ke dalam card reader untuk dimasukkan dalam laptop. Software SDformatter memastikan pengguna untuk dapat memilih drive yang akan dituju untuk proses instalasi sistem operasi, dalam hal ini adalah drive dari SD card. Kemudian klik tombol format untuk proses penghapusan drive. Setelah itu aplikasi Win32Disklmager digunakan, proses ini membutuhkan berkas dari sistem operasi Raspbian yang telah didownload sebelumnya dan harus dipastikan device yang dipilih adalah drive SD card. Tombol Write digunakan sebegai proses penanaman Raspbian dan proses ini akan berlangsung selama beberapa menit. Kartu SD yang telah dimasukkan sistem operasi Raspbian, proses selanjutnya yaitu menempatkan kartu SD tersebut ke dalam Raspberry Pi dan siap untuk digunakan. Perintah sudo raspi-config digunakan untuk mengatur beberapa fungsi konfigurasi yang paling umum. 
Konfigurasi bird repellent device dapat dilakukan dengan proses remote Raspberry Pi dengan menggunakan laptop bersistem operasi Windows. Untuk dapat mengoperasikan Raspberry Pi di Windows dibutuhkan perangkat lunak bernama Putty. Software ini berjalan berbasis text sedangkan aplikasi hasil instalasi Raspbian dalam SBC ini yang berjalan dengan GUI (Graphical user interface) dibutuhkan software VNC Viewer.

Tahapan awal penggunaan perangkat lunak VNC Viewer di laptop yaitu dengan mengetahui alamat IP dari Raspberry Pi yang terhubung melalui port LAN dengan menggunakan IP Scanner. Jika telah mengetahui alamat IP pada Raspberry Pi, tahapan selanjutnya yaitu memasukkannya ke dalam aplikasi PuTTY. Setelah terjalin komunikasi yang baik dengan memasukkan username dan password dari Raspberry Pi, maka proses remote pun akan dimulai. Perintah yang digunakan untuk proses remote Raspberry Pi menggunakan VNC Viewer adalah sudo raspi-config - Interfacing Options - P3 VNC Enable. Selanjutnya software VNC Viewer dibuka dan IP Address Raspberry Pi yang telah diketahui dimasukkan ke dalamnya lalu enter. Setelah berhasil akan keluar tampilan login Raspberry Pi, masukkan username dan password yang telah dibuat sebelumnya. Hal ini menunjukkan bahwa penggunaan VNC Viewer telah berhasil.

Aplikasi lain yang mendukung system bird repellent device adalah Python dan OpenCV. Keduanya merupakan perangkat lunak yang berfungsi sebagai bahasa pemrograman dan library pendukung dalam proses stream pada sensor kamera Logitech, dan juga mengaplikasikan dan membuat perintah agar hanya objek burung saja yang dapat mengaktifkan aktuator berupa speaker. Pada perancangan perangkat lunak ini menggunakan bahasa pemrograman Python yang dimana urutan programnya diubah sesuai kebutuhan pengguna. Pada bagian inilah pembelajaran dalam (deep learning) menggerakkan sistem untuk menentukan bahwa objek yang dipantau adalah burung atau bukan.

\begin{tabular}{|l|l|}
\hline \multicolumn{1}{|c|}{$\begin{array}{l}\text { mo1 } \text { monitorburung } \\
\text { bot }\end{array}$} \\
\hline Terdeteksi ada burung sebanya \\
\hline Terdeteksi ada burung sebanya \\
\hline Terdeteksi ada burung sebanya \\
\hline Terdeteksi ada burung sebanya \\
\hline Terdeteksi ada burung sebanya \\
\hline Terdeteksi ada burung sebanya \\
\hline Terdeteksi ada burung sebanya \\
\hline Terdeteksi ada burung sebanya \\
\hline Terdeteksi ada burung sebanya \\
\hline Terdeteksi ada burung sebanya \\
\hline Terdeteksi ada burung sebanya \\
\hline
\end{tabular}

Gambar 3. Pengujian Notifikasi Bird Repellent Device pada Smartphone

Gambar 3 menunjukkan pengujian dini yang telah dilakukan untuk mengetahui proses notifikasi melalui telegram berjalan dengan baik. Hal ini menunjukkan bahwa proses deteksi dengan menggunakan kamera sudah berjalan dan konfigurasi mengenai komunikasi antara sistem bird repellent device melalui internet sudah berhasil dan mendeteksi adanya burung. Sejalan dengan notifikasi, aktuator pun berjalan sebagai mestinya.

\section{KESIMPULAN}

Penelitian ini sejalan dengan visi para kelompok tani agar dalam masa panen memiliki hasil yang melimpah tanpa gangguan misalnya serangan burung. Tujuan perancangan perangkat pengusir burung dengan mikrokontroler Raspberry Pi ini, diharapkan dapat menciptakan beberapa dampak positif seperti menyediakan fasilitas berupa teknologi yang dapat membantu mengatasi serangan burung di area persawahan secara tepat waktu dengan memanfaatkan Internet of Things, kemudian memberikan kemudahan bagi kelompok tani untuk mendapatkan hasil panen yang optimal dan dapat meminimalisir jumlah serangan burung di sekitar area persawahan. 
Berdasarkan analisa dan evaluasi dini serta perbaikan terhadap permasalahan yang telah dilakukan dalam perancangan sistem ini, dapat ditarik kesimpulan bahwa prototipe ini dapat mengeluarkan suara frekuensi yang efektif dalam proses mengusir hama burung. Purwarupa ini terdiri dari Raspberry Pi sebagai pengendali utama alat pendeteksi hama burung yang terhubung ke sensor kamera sebagai input dan aktuator speaker, GSM modul sebagai output. Kamera sebagai alat pendeteksi hama burung akan mengirimkan data kepada SBC, kemudian Raspberry pi mengolah data tersebut untuk selanjutnya dikirimkan sebuah perintah untuk mengeluarkan frekuensi suara apabila hama burung terdektesi.

Sistem yang dibangun ini tentunya masih dalam tahapan pengembangan agar menjadi lebih baik. Pemilihan terhadap SBC ini merupakan bagian dari penelitian awal, masih ada beberapa SBC lain yang tentunya lebih kuat dan lebih mampu melakukan proses komputasi yang lebih berat, karena proses pengolahan citra tentunya mempunyai beban komputasi yang tidak sedikit. Kemudian kondisi alam pun menjadi perhatian penting, mengingat sawah merupakan kawasan yang sangat luas dan sering terdapat kendala baik jangkauan area tangkapan kamera, cuaca dan petir.

Peluang riset yang akan datang tentu saja masih berkisar pada pengembangan ketelitian dan ketepatan deteksi terhadap objek yang dituju, efektivitas dan pengukuran sejauh mana aktuator mengambil peran dalam teknik pengusiran burung serta kumpulan data dari banyaknya burung yang terdeteksi dapat dijadikan unsur penunjang keputusan. Selain dari itu, luasnya area sawah juga menjadikan faktor penting dalam membangun wireless sensor network [13] layaknya sensor kamera pada pemantuan dalam pedestrian atau pejalan kaki agar dapat mendukung pengembangan industri 4.0 di area pertanian.

\section{UCAPAN TERIMA KASIH}

Penulis ingin mengucapkan terima kasih kepada DRPM Ristekdikti yang memberikan kesempatan untuk melakukan penelitian. Penulis juga berterima kasih kepada kerabat kelompok tani, tim UPT BPP Labuan, STMIK Raharja dan Universitas Raharja yang memberikan dukungan dan bantuan dalam melakukan penelitian.

\section{DAFTAR PUSTAKA}

[1] Wei, Y., et al. 2015. "Design of Agricultural Aircraft with Audio Anti-bird". in Fifth International Conference on Instrumentation and Measurement, Computer, Communication and Control (IMCCC), Qinhuangdao.

[2] Meng, X., et al. 2010. "The device of ultrasound driving bird”. in World Automation Congress, Kobe.

[3] Muminov, A., et al. 2017. "Development of a solar powered bird repeller system with effective bird scarer sounds". in International Conference on Information Science and Communications Technologies (ICISCT), Tashkent.

[4] Takeki, A., et al. 2016. "Combining deep features for object detection at various scales: finding small birds in landscape images". IPSJ Transactions on Computer Vision and Applications 8. 5, 1-7.

[5] Chen, Z., et al. 2011. "Charms - China Agricultural Remote Sensing Monitoring System". in IEEE International Geoscience and Remote Sensing Symposium, 3530-3533.

[6] Roihan, A., Permana, A., \& Mila, D. 2016. "Monitoring kebocoran gas menggunakan mikrokontroler arduino uno dan esp8266 berbasis internet of things". ICIT (Innovative Creative and Information Technology) 2. 2, $170-183$.

[7] Supriyono, I. A., Sudarto, F., and Fakhri, M. K. 2016. "Pengukur tinggi badan menggunakan sensor ultrasonik berbasis mikrokontroler atmega328 dengan output suara". CCIT Journal 9. 2, 148-156.

[8] Roihan, A., Sunarya, P. A., and Wijaya, C. 2018. "Auto tee prototype as tee golf automation in golf simulator studio". In 2018 6th international conference on cyber and it service management (citsm), 1-5.

[9] Sutrisno, S., Kristiadi, D. P., and Supriyanti, D. 2017. "Aplikasi sistem pakar untuk mendiagnosa gangguan jaringan lan berbasis android di sekolah kemurnian Jakarta". SENSI Journal. 3. 2, 221-239.

[10] Ilamsyah, Setyawan, H. I., Syahfitri, A. 2017. "Robot Pencari Benda Menggunakan Perintah Suara Berbasis Arduino Uno". CERITA (Creative Education of Research In Information Technology and Artificial Informatics). 3. 2, 206-216.

[11] Harington, W. (2015). Learning Raspbian. Brimingham: Packt Publishing.

[12] Sunarya, A., Santoso, S., and Sentanu, W. 2015. "Sistem pakar untuk mendiagnosa gangguan jaringan lan". CCIT Journal. 8. 2, 1-11.

[13] Wu, D. P., et al. 2015. "A hierarchical packet forwarding mechanism for energy harvesting wireless sensor networks”. IEEE Communication Magazine, 53. 8, 92-98. 